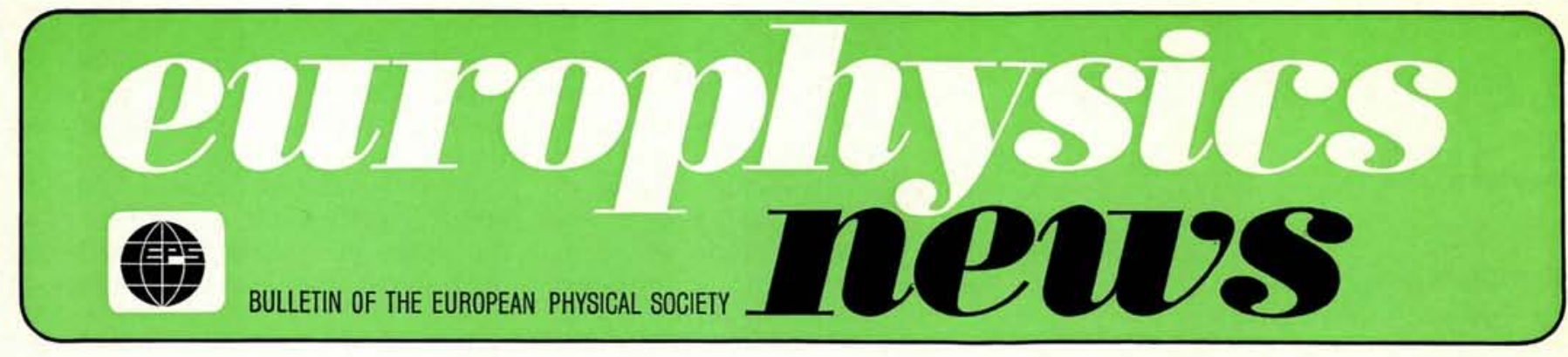

\title{
Let us not be discouraged
}

\author{
H.B.G. Casimir, President
}

The situation is really very simple: the income of EPS has increased more slowly than the expenditure. We have been able to attract several new Associate Members, we have received subsidies and donations, yet we have been overspending - and we cannot continue to do that. Therefore, rather drastic measures were unavoidable, are now being taken, and will be reported in Europhysics News, as soon as all the details have been worked out. It is my firm conviction, however, that it will be possible to make these adjustments they relate mainly to the running of the Main Secretariat and the editing of Europhysics News - without impairing the actual work of the Society and without endangering its future. It is about this work and this future that I should like to write a few words.

In an area like Europe, with its enormous diversity of languages, cultural and historical traditions, and governmental structures, the aim of a society like EPS cannot possibly be to coordinate all activities of national societies and, even less, to organize the actual research work. Our task, as I see it, is to contribute to communication: to communication between physicists working in different countries but in the same disciplines, between physicists in different disciplines, between older and younger generations of physicists, between physicists and other scientists, between physics and society-at-large.
The work of our Divisions and of our Advisory Committees can always be brought under one of these headings and significant contributions have been made. Many conferences, study conferences, summer schools, have been - and are being - organized by our Divisions, many more have been sponsored by EPS. Sceptics may ask whether many of the sponsored conferences could not have been held just as well without EPS. The answer is that they might have been held, but not quite as well. The sponsorship implies that the organizers have to pay due attention to international aspects and it promotes and facilitates international participation. Similarly, although the work of the Publications Committee is only a first step towards a more efficient arrangement of publications in physics, the granting of the 'Europhysics Journal' label to a selected number of journals has helped several of these journals to become both more international and more specialized, has contributed towards unification of standards, and has definitely improved their coverage by abstracting services.

But it is not my intention to survey all the work of EPS. What I want to emphasize is that all these activities, now that they have been started, can go on, and will go on, even if the Main Secretariat cannot provide quite the same administrative services and cannot participate quite as actively as it has until now. And Europhysics
News will continue as an indispensable link between members, although there also economies will have to be made.

I see no reason to be pessimistic about the future of EPS. We shall have to depend even more than heretofore on the voluntary efforts of our members, but about this I have no misgivings. Travelling around Europe, visiting meetings of member societies, talking with individual physicists and attending meetings of our own Advisory Committees, I have again and again been struck by the interest in EPS, by the willingness to collaborate.

I began by saying that the situation is simple. My conclusion is also a simple one:

Let us be realistic, but let us not be discouraged.

\section{Contents}

Let us not be discouraged 1

Letters to the Editor . . . 2

French Physics Teaching . 4

Society News . . . . 6

Molecular Spectroscopy . . 7

Meetings . . . . . . 8 